\title{
Crossbite: Expansion of authors in scientific articles
}

"Scientific vanity makes for poor evidence of knowledge." Marquis of Maricá

In these times of "scientometrics", it seems prudent to ponder the number of authors that should together compose a scientific article. Taking it one step further, I'd like to address the cross-reverberation that results from the expansion of authorship without effective author participation, and its impact on the neoformation of the morals and ethics of our young researchers.

Just recently, an article with eight authors was submitted to the Dental Press Journal of Orthodontics (DPJO). The number in itself is elusive and one should not jump to conclusions. It would be prejudicial - pure and simple - to do so. It is common for journals such as Nature and Science, to cite two of the most prestigious journals worldwide, to publish articles with dozens and dozens of authors. It would be naive, however, to deny that the need to publish, compelled by competition, has led some scientists to become oblivious to science as the foundation of truth, and even less so to ethics as philosophy. This question seems too important to overlook, too challenging to avoid.

The article in question, submitted to DPJO, presented data on a rather basic laboratory test, and nothing could justify the overwhelming number of authors. In itself, the content of the article precluded its publication, and the excessive number of authors caused atresia in the editor's confidence regarding the purposes of the study. The article was submitted by a young researcher and it seems logical to believe that he may have been hard pressed to expand the list of author names to include some of his tutors. "Example is always more effective than theory," wrote Englishman Samuel Johnson. Not only that, but the young man saw it fit to expand even further the authorship and added the names of some of his class('mates').
Could this need for scientific output be a condition somatically imposed by our culture? In seeking to clarify the issue, I reviewed the original articles published in the two most prestigious orthodontic journals worldwide in the year 2012. I perceived that the articles published by Brazilians include on average one author more than articles published by authors from other countries $(p<0.01)$. The average - median, to be exact - Brazilian articles have five authors, whereas other nationalities exhibit a median of four per article.

Why is it that articles published by Brazilian orthodontists have, on average, one extra author? One plausible explanation could be the difficulties involved in writing in the English language. It would make sense, therefore, to include an author with indepth knowledge of English. This explanation falls apart when we realize that the educational level of Brazilian orthodontists who publish in prestigious scientific journals is too high to regard the English language as a major barrier. Another thesis that might justify this phenomenon has to do with the increasing number of studies from non-English speaking countries published in these journals. Therefore, many researchers in Turkey, Japan, China and some European countries would purportedly encounter difficulties to publish in the language of Shakespeare.

The inclusion of authors who actually did not contribute anything to a given study is a breach of ethics, as well as unfair competition to virtuous professionals. Nevertheless, it would be naive to believe that this practice affects Brazilian researchers exclusively. In reviewing the two leading international journals of orthodontics I found an article with nine authors. It pertained to an in vitro assay to examine bond strength using different etching agents. In my view, nothing justifies such a large number of authors. 
This issue permeates orthodontics. Even firstrate journals are not immune to this problem. In 2002 , one out of every ten authors of articles published in the British Medical Journal (BMJ), and one out of five authors of the Annals of Internal Medicine comprised authorship credit without proper justification. ${ }^{1}$ In the latter, it is estimated that $60 \%$ of published articles had at least one "fake" author.

According to the International Committee of Medical Journal Editors (ICMJE), someone should only be considered "author" if their intellectual contribution is substantial. ${ }^{2}$ Some journals request and publish information about the contributions of each author. Editors have been strongly encouraged to implement a policy of identifying the person responsible for the integrity of the work, and the role each author plays in the study. Journals such as Nature, BMJ, The Lancet, PLoS and JAMA have followed these guidelines. In dentistry as well as orthodontics, this is a little known practice.

In early 2012, the DPJO launched the policy of identifying each author in the studies submitted to it. Today, the submission system accepts up to four authors. This does not prevent the corresponding author from including more names, but it does require a statement to the editor about the role of each researcher in the study. This new policy has yielded impressive results, and the overblown expansion referred above is showing signs of constriction. In recent years (2010 and 2011), approximately $46 \%$ of the articles published in DPJO had five or more authors. Almost ten months after this adjustment only $7 \%$ of the corresponding authors justified the inclusion of more than four authors.

The International Committee of Medical Journal Editors (ICMJE) determines that all those who have collaborated in a study but do not meet the criteria for authorship be listed in the acknowledgments section. People who have provided purely technical help, text revision, or department colleagues who have provided generic support should only be included in this section. In my editorials, I relied on the help of my brother, a thoracic surgeon who also boasts considerable skill in crafting eloquent words in a concise fashion. My "ghost-writer" spent part of his scant free time helping me tackle the difficult task of producing a clearer, purposeful and polished text. In this editorial, for example, he played a primary role mitigating the inherent roughness of the subject. It so happens that some wounds might be exposed. Therefore, surgical treatment in the choice of words could render the predicament less unpleasant, since pain seems inevitable. For this "textoplasty" - although not strictly a coauthorship - failing to thank him would be a gesture of ingratitude.

\section{David Normando - Editor-in-Chief davidnormando@hotmail.com}

\section{ACKNOWLEDGEMENTS}

I would like to thanks to Prof. Roger Normando for the critical analysis and suggestions in the text organization and grammar conference.

\section{REFERENCES}

1. Bates T, Anić A, Marusić M, Marusić A. Authorship criteria and disclosure of contributions: comparison of 3 general medical journals with different author contribution forms. JAMA. 2004 Jul 7;292(1):86-8.

2. International Committee of Medical Journal Editors. Uniform requirements for manuscripts submitted to biomedical journals: ethical considerations in the conduct and reporting of research: authorship and contributorship. [accessed on 2012 Oct 30]. Available from: www.icmje.org/ethical_lauthor.html. 